\title{
Capacity Choice of Dams under Rivalry Use and Externalities
}

\author{
Harold Houba' \\ Kim Hang Pham Do \\ Xueqin Zhu ${ }^{3}$
}

1 Faculty of Economics and Business Administration, VU University Amsterdam, the Netherlands;

2 Massey University, New Zealand;

3 Wageningen University, the Netherlands. 
Tinbergen Institute is the graduate school and research institute in economics of Erasmus University Rotterdam, the University of Amsterdam and VU University Amsterdam.

More TI discussion papers can be downloaded at http://www.tinbergen.nl

Tinbergen Institute has two locations:

Tinbergen Institute Amsterdam

Gustav Mahlerplein 117

1082 MS Amsterdam

The Netherlands

Tel.: +31(0)205251600

Tinbergen Institute Rotterdam

Burg. Oudlaan 50

3062 PA Rotterdam

The Netherlands

Tel.: +31(0)10 4088900

Fax: $+31(0) 104089031$

Duisenberg school of finance is a collaboration of the Dutch financial sector and universities, with the ambition to support innovative research and offer top quality academic education in core areas of finance.

DSF research papers can be downloaded at: http://www.dsf.nl/

Duisenberg school of finance

Gustav Mahlerplein 117

1082 MS Amsterdam

The Netherlands

Tel.: +31(0)20 5258579 


\title{
Capacity Choice of Dams under Rivalry Use and Externalities
}

\author{
Harold Houba*, Kim Hang Pham Do** and Xueqin Zhu*** \\ *Department of Econometrics and OR, VU University Amsterdam, and \\ Tinbergen Institute, Amsterdam, the Netherlands. \\ ${ }^{* *}$ School of Economics and Finance, Massey University, Palmerston North, New Zealand. \\ ${ }^{* * *}$ Environmental Economics and Natural Resources Group, Wageningen University,
}

Wageningen, the Netherlands.

\begin{abstract}
This paper studies the relation between optimal dam capacity and water management under rivalry uses and externalities. We extend the hydropower generation model, based on Haddad (2011), by including the competing use of water resource, non-linear building cost of dam capacity and externalities in a welfare optimization model. We obtain the optimal dam capacity for multi-functional dams such as providing infrastructure for industrial and households water use, conjunctive use of hydropower generation and irrigation; storing water in the wet season for use in the dry season, and mitigating flooding damages. The optimal solution shows that optimal dam capacity is characterized by the marginal benefits of hydropower generation, the marginal costs of flooding damages, and the constraining factors. Moreover, the optimal water management can be achieved by using derived seasonal prices in a decentralized manner.
\end{abstract}

Keywords: OR in environment and climate change, river-basin management, dam capacity, welfare optimization, externalities.

JEL CODES: C71,C72,D62

\section{Corresponding author}

Harold Houba, Department of Econometrics and OR, VU University Amsterdam. harold.houba@vu.nl 


\section{Introduction}

Dams have made an important and significant contribution to human development, and the benefits derived from them have been considerable. Dams were built to provide water for irrigated agriculture, industrial and domestic (households) use, to generate hydropower or to help control floods. But dams also altered and diverted river flows, resulting in significant impacts on livelihoods, fishery and the environment (Dugan et al., 2010; Beck et al., 2012). The latter impacts are the so-called social costs. Often dams are built for multiple of these purposes. For example, electricity generation is an important reason for building large dams in many countries, either as the primary purpose, or as an additional function such as regulating water use in different seasons. Decision-making on dam capacity choice should, therefore, trade off different water uses and take into account the possible adverse impacts.

As dams have been an important means of meeting needs for water and energy services, optimal dam capacity for hydropower generation and its efficient operation are important. Recently, Haddad (2011) studies capacity choice and hydropower generation in a deterministic model with two seasons from the perspective of the dam operator. All social costs, including those for environmental externalities, are said to be incorporated in the building costs of dams and are assumed to be linear. However, for the study of environmental issues concerning dams and their operation this assumption is somewhat oversimplified. Our main research questions are thus: what is the optimal dam capacity considering multiple purposes and including the possible social costs caused by externalities? The aim of this paper is to study some externalities of dams based the model of Haddad (2011) by explicitly modelling the rivalry use of water and the social costs (e.g. flood damages).

We consider the following major economic functions of dam capacity building: it provides infrastructure for industrial and households' water use, hydropower generation, flood damage mitigation and agricultural irrigation. Therefore, we consider multiple functions of dams. Water use among different users is rival, i.e. there is competition among industry and households, and a hydropower generator. However, water use for irrigation and hydropower generation is non-rival or conjunctive, because irrigation water is withdrawn after hydropower is generated. Furthermore, we also consider the seasonal variations in water availability or inflows. We represent all these aspects in a welfare optimization model (see e.g. Zhu and van 
Ierland, 2012). Houba et al. (2013) perform a numerical analysis of such as a model that is calibrated for the Mekong River. However, the Mekong River is just one specific case of a wide diversity of realistic cases, which cannot inform policy makers in different river basins about the economic issues in their specific basin management. Solving the model analytically gives some interesting results on the choices of dam capacities under different specific cases of reality, such as dams solely used for flooding control, for irrigation, or for hydropower generation. Our contribution of this paper is to characterize the relations between optimal dam capacity and water management under rivalry uses and externalities. We view this paper complementary to Houba et al. (2013).

The paper is organized as follows. The next section presents the basic model that extends the model of Haddad (2011) in which dam capacity is endogenous. Section 3 presents the general case of Pareto efficient dam capacity and its operation. It also discusses the welfare costs of neglecting rivalry use and externalities. Section 4 discusses the implications of the model results based on three special cases of single purpose dams: a dam is used solely for flood control, for irrigation and for hydropower generation respectively. Concluding remarks follow in the last section.

\section{The Model}

Following Haddad (2011), our model respects the hydrological basin reality. Total water available is determined by seasonal precipitation or water inflows. We distinguish two seasons, the wet season $(w)$ and the dry season $(d)$. There is an option to build a dam with a certain capacity, denoted by $D$. The dam is used as infrastructure (a reservoir) to provide end users such as industry and households with water, and it is also used for hydropower generation and to store water from the wet season, denoted by $y$, for usage in the dry season. Due to evaporation losses and leakage from the dam, only $\delta y, \delta \in(0,1)$, can be used in the dry season. ${ }^{1}$ Water availability, including inflows and river flows, determine water usage in each season $\tau=w, d$. Water users are aggregated into three categories of representative consumers: Industry and households, irrigated agriculture and a hydropower generator.

The water balances

\footnotetext{
${ }^{1}$ Haddad (2011) assumes $\delta=1$.
} 
Our model extends Haddad (2011) by including other water uses (e.g. industry and households, irrigation) and flood damage. The river basin is presented in Figure 1. In the wet season $w$, inflow $f_{w}$ can be spent on consumptive use by industry and households $x_{w}$, storage $y$ for the dry season, hydropower generation $q_{w}$ that is reusable further downstream, and pass-through by the dam to downstream. River outflow from the dam $o_{w}$ consists of $q_{w}$ and pass-through that runs directly to downstream and might cause flood damage. In season $d$, inflow $f_{d}$ and the fraction of stored water $\delta y$ can be spent on water use $x_{d}$, hydropower generation $q_{d}$ that remains available further downstream, and pass-through by the dam to downstream. River outflow from the dam $o_{d}$ can be used either for irrigation $i_{d}$ (assuming an irrigation infrastructure that is independent of capacity $D$ ) or runs to downstream. This imposes $i_{d} \leq o_{d}$. Formally, upstream's water balances ${ }^{2}$ are given by

$$
\begin{aligned}
x_{w}+y+q_{w} & \leq f_{w}, \\
x_{w}+y+o_{w} & =f_{w}, \\
x_{d}+q_{d} & \leq f_{d}+\delta y, \\
x_{d}+o_{d} & =f_{d}+\delta y, \\
i_{d} & \leq o_{d} .
\end{aligned}
$$

In Figure 1, both $o_{w}$ and $o_{d}$ are expressed as the residuals from inflow minus water use. The total use of water must not exceed the available dam capacity $D$. Dam capacity $D$ imposes the restrictions

$$
\begin{aligned}
x_{w}+y+q_{w} & \leq D, \\
x_{d}+q_{d} & \leq D .
\end{aligned}
$$

This completes the description of the water balances.

Benefits and costs

There are three water users that create economic value. Consumptive use by industry and households permanently remove amounts of water in both wet and dry seasons. The economic value is $v_{\tau}\left(x_{\tau}\right)$, a concave function with satiation point $\bar{x}_{\tau}>0$. Both, $x_{w}$ and

\footnotetext{
${ }^{2}$ This formulation extends the model in Haddad (2011) to include the industrial and households' water use.
} 


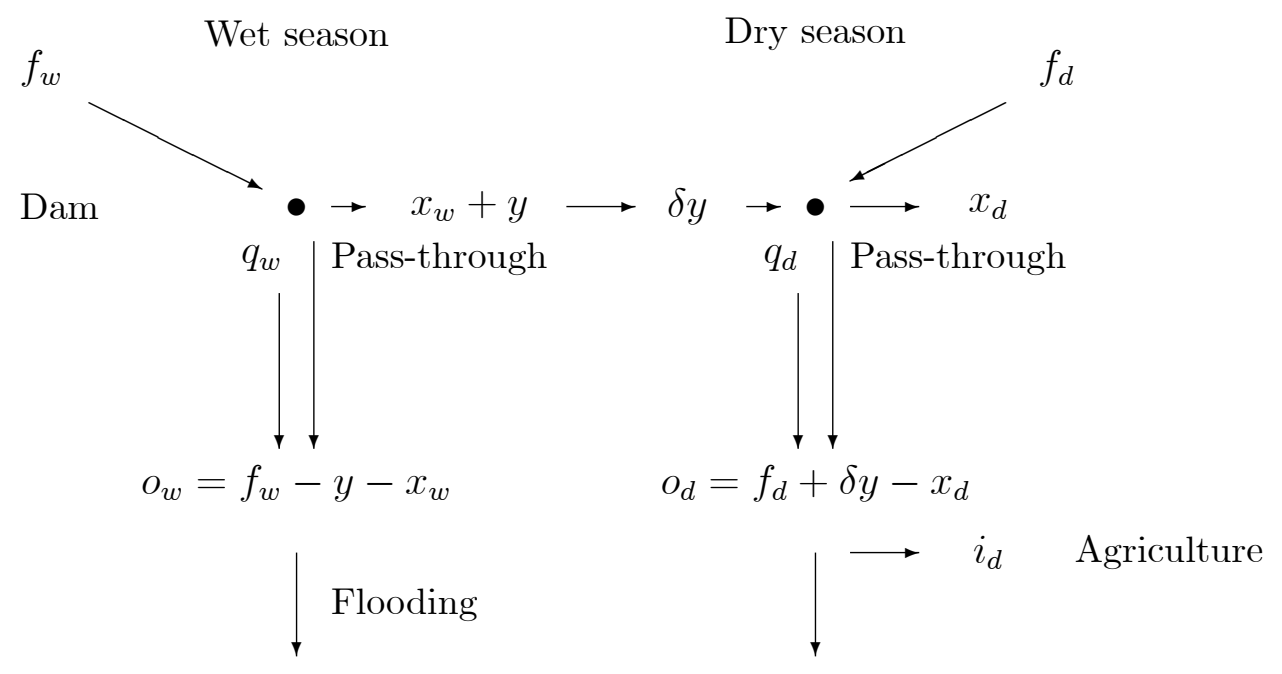

Figure 1: Seasons, storage and water uses.

$x_{d}$ are externalities for downstream, as is storage $y$. The net benefits from hydropower in season $\tau$ are $h_{\tau}\left(q_{\tau}\right)$, a concave function with satiation point $\bar{q}_{\tau}>0$. The net benefits from irrigation in season $d$ are $a_{d}\left(i_{d}\right)$, a concave function with satiation point $\bar{l}_{d}>0$.

The costs of building dam capacity $D$ including costs for storing water are $c(D)$, a convex function with $c^{\prime}(D)>0 .{ }^{3}$ These costs include the annuities of the capital costs, the operation and maintenance costs and evaporation losses. River flows also involve costs associated with flooding in the wet season. The costs of flood damage are $c_{w}\left(o_{w}\right)$, a convex function with $c_{w}^{\prime}\left(o_{w}\right)>0$.

The annual economy's welfare function $u\left(x_{w}, x_{d}, q_{w}, q_{d}, i_{d}, D, o_{w}, o_{d}\right)$ is given by

$$
v_{w}\left(x_{w}\right)+v_{d}\left(x_{d}\right)+h_{w}\left(q_{w}\right)+h_{d}\left(q_{d}\right)+a_{d}\left(i_{d}\right)-c(D)-c_{w}\left(o_{w}\right) .
$$

From this objective function, it is clear that our model includes flood damage, the benefits from consumptive use and irrigation, and allows nonlinear building costs. This completes the description of costs and benefits of dam capacity building and water management (allocation among different users).

\section{Pareto efficient management}

In this section, we investigate Pareto efficient management of dams. Because the derivations are quite technical we defer these to the appendix. In what follows we discuss the main results.

\footnotetext{
${ }^{3}$ Haddad (2011) assumes constant costs of building dam capacity.
} 
Pareto efficient management internalizes all externalities by maximizing the welfare function (8). After substituting out the flow variables $o_{w}$ and $o_{d}$ from (2) and (4), we obtain the following welfare optimization program:

$$
\begin{array}{r}
\max _{x_{w}, x_{d}, q_{w}, q_{d}, i_{d}, D, y} v_{w}\left(x_{w}\right)+v_{d}\left(x_{d}\right)+h_{w}\left(q_{w}\right)+h_{d}\left(q_{d}\right)+a_{d}\left(i_{d}\right) \\
-c(D)-c_{w}\left(f_{w}-x_{w}-y\right),
\end{array}
$$

$$
\begin{array}{lll}
\text { s.t. } & \\
x_{w}+y+q_{w} & \leq f_{w}, & \left(p_{w}\right) \\
x_{d}+q_{d} & \leq f_{d}+\delta y, & \left(p_{d}\right) \\
i_{d} & \leq f_{d}+\delta y-x_{d}, & \left(\lambda_{d}\right) \\
x_{w}+y+q_{w} & \leq D, & \left(\mu_{w}\right) \\
x_{d}+q_{d} & \leq D, & \left(\mu_{d}\right)
\end{array}
$$

where all symbols between brackets denote shadow prices.

The most realistic scenario is that $D<f_{w}$, which is the case in most south-east Asia countries. Therefore, the fourth constraint holds with equality, and we substitute $y=$ $D-x_{w}-q_{w}$ in the first and fourth constraints. This eliminates these two constraints and we will solve the reduced optimization problem. Due to the assumptions we have made on the benefits and costs of water use and dam capacity building, the resulting welfare optimum is unique. In our analysis, we only characterize the case in which all variables $x_{w}, x_{d}, q_{w}$, $q_{d}, i_{d}$ and $D$ are positive in the optimum. We do so, because it is the most interesting and relevant case and this limits the number of possible boundary cases to discuss.

Our first result is discussed in the following Proposition.

Proposition 3.1 In the unique welfare optimum of (9), it holds that

$$
\begin{aligned}
v_{w}^{\prime}\left(x_{w}\right) & =h_{w}^{\prime}\left(q_{w}\right)-c_{w}^{\prime}\left(f_{w}+q_{w}-D\right), \\
v_{d}^{\prime}\left(x_{d}\right) & =h_{d}^{\prime}\left(q_{d}\right)+a_{d}^{\prime}\left(i_{d}\right), \\
i_{d} & =\min \left\{\bar{\imath}_{d}, q_{d}\right\} \text { and } \lambda_{d}=a_{d}^{\prime}\left(i_{d}\right) .
\end{aligned}
$$

Moreover, $h_{w}^{\prime}\left(q_{w}\right) \geq c_{w}^{\prime}\left(f_{w}+q_{w}-D\right)$ and $q_{w}<\bar{q}_{w}$.

Proposition 3.1 reflects that the use of dam capacity in the wet season for hydropower generation is rival to water that is used first for consumptive use of industry and households and then for irrigation. Condition (10) illustrates the rivalry use of water in the wet season. The marginal benefit of consumptive use by the industry and household sector should be 
equal to the marginal benefit of hydropower generation after deducting the incremental costs of its flood damage, i.e. the cost of its negative externality. Since the marginal benefit of consumptive use is nonnegative, the marginal benefit of hydropower generation should exceed the incremental costs of the flood damage hydropower generation causes. Satiation of consumptive use in the wet season can only occur if the marginal benefits of hydropower generation equal the marginal cost of flood damage in this season. Satiation of hydropower generation in the wet season can never occur, because this activity causes flooding as an externality. Therefore, $q_{w}<\bar{q}_{w}$ has to hold.

Similarly, condition (11) illustrates the rivalry use of water in the dry season between consumptive use and irrigation. Because water for irrigation first passes the dam before it can be used, this part of the water can be utilized twice, namely hydropower generation before irrigation takes place. In other words, hydropower generation augments the benefits from irrigation. Then, condition (11) states that the marginal benefit of water used by the industry and household sector should be equal to the marginal benefit of hydropower generation augmented by the incremental benefits of reusing the water for hydropower generation for irrigation. Obviously, $v_{d}^{\prime}\left(x_{d}\right) \geq a_{d}^{\prime}\left(i_{d}\right)$ and $v_{d}^{\prime}\left(x_{d}\right) \geq h_{d}^{\prime}\left(q_{d}\right)$. Satiation of consumptive use in the dry season can only occur if both hydropower generation and irrigation are satiated as well in this season. The fact that irrigation water first passes the dam implies $i_{d}=$ $\min \left\{\bar{\imath}_{d}, q_{d}\right\}$.

For the two crucial shadow prices $p_{d}$ and $\mu_{d}$, we derive the following result.

Proposition 3.2 In the unique welfare optimum of (9), it holds that

$$
h_{w}^{\prime}\left(q_{w}\right) \leq c^{\prime}(D) \leq h_{w}^{\prime}\left(q_{w}\right)+h_{d}^{\prime}\left(q_{d}\right)
$$

and $\mu_{d}, p_{d} \in\left[0, h_{d}^{\prime}\left(q_{d}\right)\right]$ are given by

$$
\begin{aligned}
& \mu_{d}=c^{\prime}(D)-h_{w}^{\prime}\left(q_{w}\right), \\
& p_{d}=h_{d}^{\prime}\left(q_{d}\right)+h_{w}^{\prime}\left(q_{w}\right)-c^{\prime}(D) .
\end{aligned}
$$

Moreover, $\mu_{d}=0$ and $p_{d}=h_{d}^{\prime}\left(q_{d}\right)$ if and only if $c^{\prime}(D)=h_{w}^{\prime}\left(q_{w}\right)$. Similarly, $\mu_{d}=h_{d}^{\prime}\left(q_{d}\right)$ and $p_{d}=0$ if and only if $c^{\prime}(D)=h_{w}^{\prime}\left(q_{w}\right)+h_{d}^{\prime}\left(q_{d}\right)$. 
Although there are many economic activities and externalities related to water, the shadow prices $p_{d}$ and $\mu_{d}$ can be fully characterized by the marginal benefits from hydropower generation and the marginal costs of dam capacity. These shadow prices hint at that externalities do not play a role, but one should realize that hydropower generation causes externalities (e.g. flood damage downstream), and such activity can be regarded as the gateway through which external economic values enter the dam facility. This becomes apparent if Propositions 3.1 and 3.2 are combined, we can rewrite the shadow prices as

$$
\begin{aligned}
& p_{d}=v_{w}^{\prime}\left(x_{w}\right)+v_{d}^{\prime}\left(x_{d}\right)+c_{w}^{\prime}\left(f_{w}+q_{w}-D\right)-a_{d}^{\prime}\left(i_{d}\right)-c^{\prime}(D), \\
& \mu_{d}=c^{\prime}(D)-v_{w}^{\prime}\left(x_{w}\right)-c_{w}^{\prime}\left(f_{w}+q_{w}-D\right) .
\end{aligned}
$$

Hence, externalities of dams such as flood damage or less water for irrigation do enter these prices.

Note that the existence of an optimal welfare solution implies that the shadow prices in Proposition 3.2 are nonnegative. Hence, the marginal benefits from hydropower generation in the wet season are bounded by the marginal costs of dam capacity, i.e. $h_{w}^{\prime}\left(q_{w}\right) \leq c^{\prime}(D)$ has to hold in the welfare optimum. This suggests that marginally expanding dam capacity further for solely increasing this activity should not be beneficial. Although externalities seem absent from $h_{w}^{\prime}\left(q_{w}\right) \leq c^{\prime}(D)$, these can be brought in through Proposition 3.1 to obtain $v_{w}^{\prime}\left(x_{w}\right)+c_{w}^{\prime}\left(f_{w}+q_{w}-D\right) \leq c^{\prime}(D)$. Marginally expanding dam capacity further for increasing consumptive use, and thereby marginally reducing flood damage, should not be beneficial either. Furthermore, combining Propositions 3.1 and 3.2, we obtain

$$
c_{w}^{\prime}\left(f_{w}+q_{w}-D\right) \leq h_{w}^{\prime}\left(q_{w}\right) \leq c^{\prime}(D)
$$

From these inequalities, it is immediately clear that the marginal costs of flood damage should be lower than the marginal costs of expanding dam capacity.

The solution to (9) depends upon whether the water availability (3) or dam capacity (7) or both restrict water use and hydropower generation in the dry season. Water availability in the dry season is the binding constraint, whenever $(1-\delta) D+\delta\left(x_{w}+q_{w}\right)>f_{d}$, which we call water scarcity.

Note that the nonlinearity of the functions excludes a closed-form solution. In what follows, we report for each case the nonlinear system that characterizes the optimal solution. 
Case 1: Water availability is the constraining factor in the dry season

Recall that in this case we have (3) is binding and (7) nonbinding. Define $x_{w}^{*}, x_{d}^{*}, q_{w}^{*}, q_{d}^{*}$, $i_{d}^{*}$ and $D^{*}$ as the unique solution to the following non-linear system:

$$
\begin{aligned}
v_{w}^{\prime}\left(x_{w}\right) & =h_{w}^{\prime}\left(q_{w}\right)-c_{w}^{\prime}\left(f_{w}+q_{w}-D\right), \\
v_{d}^{\prime}\left(x_{d}\right) & =h_{d}^{\prime}\left(q_{d}\right)+a_{d}^{\prime}\left(i_{d}\right), \\
i_{d} & =\min \left\{\bar{\imath}_{d}, q_{d}\right\} \\
v_{w}^{\prime}\left(x_{w}\right) & =\delta v_{d}^{\prime}\left(x_{d}\right), \\
c^{\prime}(D) & =h_{w}^{\prime}\left(q_{w}\right), \\
\text { either } q_{d} & =f_{d}+\delta\left(D-x_{w}-q_{w}\right)-x_{d}, \quad \text { or } q_{d}=\bar{q}_{d} .
\end{aligned}
$$

Obviously, the third line obeys the condition $h_{w}^{\prime}\left(q_{w}\right) \leq c^{\prime}(D)$ of Proposition 3.2. Water availability in the dry season, given by $f_{d}+\delta\left(D-x_{w}-q_{w}\right)$, constrains the three categories of water use in this season. Note also that the case $\delta<1$ is qualitatively similar to the case $\delta=1$. The unique solution to this system characterizes all values for this case.

Proposition 3.3 If $(1-\delta) D^{*}+\delta\left(x_{w}^{*}+q_{w}^{*}\right)>f_{d}$, then welfare optimal water management is given by building dam capacity $D^{*}$, industrial and households' water use $x_{w}^{*}$ and $x_{d}^{*}$, hydropower generation $q_{w}^{*}<\bar{q}_{w}$ and $q_{d}^{*}$, and irrigation $i_{d}=\min \left\{\bar{\imath}_{d}, f_{d}+\delta\left(D^{*}-x_{w}^{*}-q_{w}^{*}\right)-x_{d}^{*}\right\}$. Moreover, $\mu_{d}^{*}=0$ and $p_{d}^{*}=h_{d}^{\prime}\left(q_{d}^{*}\right) \geq 0$.

Note that $h_{w}^{\prime}\left(q_{w}\right)=c^{\prime}(D)>0$ once more implies $q_{w}<\bar{q}_{w}$. Furthermore, since $i_{d}=\bar{\imath}_{d}$, and $x_{d}=\bar{x}_{d}$ and $x_{w}=\bar{x}_{w}$ implies $c^{\prime}(D)=c_{w}^{\prime}\left(f_{w}+q_{w}-D\right)>0$, the first case includes the special case in which all but one satiation levels are reached. In this special subcase, $D$ and $q_{w}$ solve the smaller subsystem

$$
c^{\prime}(D)=h_{w}^{\prime}\left(q_{w}\right) \text { and } c_{w}^{\prime}\left(f_{w}+q_{w}-D\right)=h_{w}^{\prime}\left(q_{w}\right)
$$

Such solution is fully driven by reasons for flood control: all pass-through from the dam in the wet season is equal to zero and all outflow from the dam $o_{w}$ is used for hydropower generation. All other water is either consumed in the wet season or diverted to the dry season.

In general, after several substitutions, we obtain

$$
c^{\prime}(D)=c_{w}^{\prime}\left(f_{w}+q_{w}-D\right)+\delta\left[h_{d}^{\prime}\left(q_{d}\right)+a_{d}^{\prime}\left(i_{d}\right)\right] .
$$

The left-hand side expresses that building dam capacity for additional water storage reduces flood damage and fraction $\delta$ of this water becomes available for the double utilization of 
hydropower generation and irrigation. Note that $\delta$ can be seen as a sort of discount factor that delivers the net present value of future utilization in the dry season. All these marginal benefits should be equal to the marginal cost of expanding dam capacity.

The optimal water management can be decentralized by having seasonal water prices, and personalized taxes or subsidies per sector. In the wet season, industrial and households, and hydropower generation should all be charged a water price of $v_{w}^{\prime}\left(x_{w}^{*}\right)$ and additionally the generator should be taxed $c_{w}^{\prime}\left(f_{w}+q_{w}^{*}-D^{*}\right)$ per unit of water because his activity increases the damage of flooding. So, in total he pays $v_{w}^{\prime}\left(x_{w}^{*}\right)+c_{w}^{\prime}\left(f_{w}+q_{w}^{*}-D^{*}\right)=h_{w}^{\prime}\left(q_{w}^{*}\right)$ per unit of water. The irrigation sector is charged a water price of $\max \left\{0, a_{d}^{\prime}\left(f_{d}+\delta\left(D^{*}-x_{w}^{*}-q_{w}^{*}\right)-x_{d}^{*}\right)\right\}$, which might be zero if the river flow in the dry season $o_{d}$ is large enough. The reason is that irrigation is modelled as upstream's last water user, which can be reinterpreted as a legal system with hierarchical water users where industrial, households and the hydropower generator are served before the agricultural sector. In such a setting, a reduced water price for irrigation compared to the water price set for other sectors can be theoretically justified on the grounds of Pareto efficiency. Such practice is observed in many countries, see e.g. Cornish et al. (2004). Building dam capacity can also be decentralized by offering the dam operators a price of

$$
c^{\prime}\left(D^{*}\right)=h_{w}^{\prime}\left(q_{w}^{*}\right)=v_{w}^{\prime}\left(x_{w}^{*}\right)+c_{w}^{\prime}\left(f_{w}+q_{w}^{*}-D^{*}\right)
$$

per unit of capacity installed. In case the dam operator is the hydropower generator who also charges and collects the sales directly from industry and households, then the water management authority has to subsidize $h_{w}^{\prime}\left(q_{w}^{*}\right)-c_{w}^{\prime}\left(f_{w}+q_{w}^{*}-D^{*}\right)$ per unit of capacity built on top of the dam operator's sales against price $v_{w}^{\prime}\left(x_{w}^{*}\right)$ in case of a uniform price for industry, households and hydropower generation.

Case 2: Dam capacity is the constraining factor in the dry season

Recall that we now have that (7) is binding while (3) is nonbinding. The optimal $\hat{x}_{w}, \hat{x}_{d}$, 
$\hat{q}_{w}, \hat{q}_{d}, \hat{\imath}_{d}$ and $\hat{D}$ are the unique solution to the following non-linear system:

$$
\begin{array}{rlr}
v_{w}^{\prime}\left(x_{w}\right) & =h_{w}^{\prime}\left(q_{w}\right)-c_{w}^{\prime}\left(f_{w}+q_{w}-D\right), & \\
v_{d}^{\prime}\left(x_{d}\right) & =h_{d}^{\prime}\left(q_{d}\right)+a_{d}^{\prime}\left(i_{d}\right), & \\
i_{d} & =\min \left\{\bar{l}_{d}, q_{d}\right\} \\
v_{w}^{\prime}\left(x_{w}\right) & =\delta\left[v_{d}^{\prime}\left(x_{d}\right)-h_{d}^{\prime}\left(q_{d}\right)\right], & \\
c^{\prime}(D) & =h_{w}^{\prime}\left(q_{w}\right)+h_{d}^{\prime}\left(q_{d}\right), & \\
\text { either } q_{d} & =D-x_{d}, & \text { or } q_{d}=\bar{q}_{d} .
\end{array}
$$

Since $h_{d}^{\prime}\left(q_{d}\right) \geq 0$ the third line obeys the condition $h_{w}^{\prime}\left(q_{w}\right) \leq c^{\prime}(D)$ of Proposition 3.2. Again, the case $\delta<1$ is qualitatively similar to the case $\delta=1$. There are three striking differences between (12) and (14). The obvious one is the presence of a different binding constraint that defines each case. A more interesting difference is $c^{\prime}(D)=h_{w}^{\prime}\left(q_{w}\right)$ versus $c^{\prime}(D)=h_{w}^{\prime}\left(q_{w}\right)+h_{d}^{\prime}\left(q_{d}\right)$. The latter implies that an economic pressure for expanding dam capacity is driven by hydropower generation in both seasons, whereas the former only hydropower in the wet season provides such a pressure. Of course, the term $h_{d}^{\prime}\left(q_{d}\right)$ drops out in case $q_{d}=\bar{q}_{d}$ holds in the optimum. Another difference between (12) and (14) is $v_{w}^{\prime}\left(x_{w}\right)=\delta v_{d}^{\prime}\left(x_{d}\right)$ versus $v_{w}^{\prime}\left(x_{w}\right)=\delta\left[v_{d}^{\prime}\left(x_{d}\right)-h_{d}^{\prime}\left(q_{d}\right)\right]$.

The unique solution to system (14) characterizes the optimal values for this case.

Proposition 3.4 If $(1-\delta) \hat{D}+\delta\left(\hat{x}_{w}+\hat{q}_{w}\right)<f_{d}$, then the welfare optimal water management is given by building dam capacity $\hat{D}$, industrial and households' water use $\hat{x}_{w}$ and $\hat{x}_{d}$, hydropower generation $\hat{q}_{w}<\bar{q}_{w}$ and $\hat{q}_{d}$, and irrigation $i_{d}=\min \left\{\bar{q}_{d}, \hat{q}_{d}\right\}$. Moreover, $\hat{p}_{d}=0$ and $\hat{\mu}_{d}=h_{d}^{\prime}\left(\hat{q}_{d}\right) \geq 0$.

In this case, $c^{\prime}(D)=h_{w}^{\prime}\left(q_{w}\right)+h_{d}^{\prime}\left(q_{d}\right)>0$, the marginal costs of dam capacity is equal to the sum of the marginal benefits from hydropower generation in both seasons. The optimal dam capacity should be able to generate the optimal amounts of hydropower in both seasons. As in Case 1, we obtain (13) from (14) with a similar interpretation.

The optimal water management can be decentralized by using seasonal water prices. As in Case 1 , industry and households are charged by $v_{w}^{\prime}\left(\hat{x}_{w}\right)$ in the wet season, and the hydropower generator by $v_{w}^{\prime}\left(\hat{x}_{w}\right)+c_{w}^{\prime}\left(f_{w}+\hat{q_{w}}-\hat{D}\right)$. However in the dry season, the generator should be charged by $v_{d}^{\prime}\left(\hat{x}_{d}\right)$ but subsidized by $a_{d}^{\prime}\left(\hat{x}_{d}\right)$ because the water that passes through the dam can be used by irrigators who are willing to pay $a_{d}^{\prime}\left(\hat{x}_{d}\right)$ per unit of water.

Case 3: Water availability and dam capacity are the constraining factors in the dry season 
In this case, both (3) and (7) are binding. Define $\tilde{p}_{d}, \tilde{\mu}_{d}, \tilde{x}_{w}, \tilde{x}_{d}, \tilde{q}_{w}, \tilde{q}_{d}, \tilde{\imath}_{d}$ and $\tilde{D}$ as the unique solution to the following non-linear system:

$$
\begin{aligned}
v_{w}^{\prime}\left(x_{w}\right) & =h_{w}^{\prime}\left(q_{w}\right)-c_{w}^{\prime}\left(f_{w}+q_{w}-D\right), \\
v_{d}^{\prime}\left(x_{d}\right) & =h_{d}^{\prime}\left(q_{d}\right)+a_{d}^{\prime}\left(i_{d}\right), \\
i_{d} & =\min \left\{\bar{\imath}_{d}, q_{d}\right\} \\
\mu_{d} & =v_{d}^{\prime}\left(x_{d}\right)-\delta^{-1} v_{w}^{\prime}\left(x_{w}\right), \\
(1-\delta) D & =f_{d}-\delta\left(x_{w}+q_{w}\right), \\
\text { either } q_{d} & =f_{d}+\delta\left(D-x_{w}-q_{w}\right)-x_{d}, \quad \text { or } q_{d}=\bar{q}_{d} \text { and } \mu_{d}=p_{d}=0 .
\end{aligned}
$$

From the fourth line, we deduce that the case $\delta<1$ is qualitatively different from the case $\delta=1$, because under $\delta=1$ this line only ties two variables $\left(x_{w}, q_{w}\right)$ to $f_{d}$ leaving $D$ unrestricted and otherwise three variables are tied up. As such, we obtain insights for $\delta<1$ that are qualitatively different from Haddad (2011). Note that in case of 'or', $\mu_{d}=0$ pins down the solution further than the 'either' case. In fact, the case of 'or' coincides with the boundary of Case 1 where the condition defining Case 3 holds. It can be shown that the boundary of Case 2 is also captured by Case 3. Therefore, this case is the intermediary case between Case 1 and Case 2. Thus, system (14) completes the characterization of the unique solution for this case.

Proposition 3.5 If $(1-\delta) \tilde{D}+\delta\left(\tilde{x}_{w}+\tilde{q}_{w}\right)=f_{d}$, then the welfare optimal water management is given by building dam capacity $\tilde{D}$, industrial and households' water use $\tilde{x}_{w}$ and $\tilde{x}_{d}$, hydropower generation $\tilde{q}_{w}<\bar{q}_{w}$ and $\tilde{q}_{d}$, and irrigation $i_{d}=\min \left\{\bar{\imath}_{d}, \tilde{q}_{d}\right\}$.

In this case, $h_{d}^{\prime}\left(q_{d}\right)+h_{w}^{\prime}\left(q_{w}\right) \geq c^{\prime}(D) \geq h_{w}^{\prime}\left(q_{w}\right)$. This means the marginal benefits from hydropower generation in the two seasons should not be smaller than the marginal costs of dam capacity. Considering the constraints from the water availability and dam capacity, we should ensure that the marginal costs of dam capacity should not be smaller than the marginal benefit of hydropower generation in the wet season. After several substitutions in (15), we obtain

$$
c^{\prime}(D)=c_{w}^{\prime}\left(f_{w}+q_{w}-D\right)+\delta\left[h_{d}^{\prime}\left(q_{d}\right)+a_{d}^{\prime}\left(i_{d}\right)+\mu_{d}\right]
$$

This reduces to (13) for the 'or' case. In case $h_{w}^{\prime}\left(q_{w}\right)<c^{\prime}(D)$, the 'either' case implies $\mu_{d}>0$ and $c^{\prime}(D)>c_{w}^{\prime}\left(f_{w}+q_{w}-D\right)+\delta\left[h_{d}^{\prime}\left(q_{d}\right)+a_{d}^{\prime}\left(i_{d}\right)\right]$. Therefore, there are stronger incentives to build dam capacity. Finally, the optimal water management can be decentralized through seasonal prices as in Case 1 and 2, which we do not elaborate on to avoid repetition. 


\section{Single-purpose dams}

This section discusses several special cases in which the dam fulfills a single purpose. We obtain clearer insights for single purpose dams and study boundary cases that are excluded in the previous section.

\subsection{Flood control}

Floods are among the world's most frequent and damaging disasters. Dams have historically been extensively used as a defence against floods. When dams are used for flood control only, we have $v_{w}\left(x_{w}\right)=0, v_{d}\left(x_{d}\right)=0, h_{w}\left(q_{w}\right)=0, h_{d}\left(q_{d}\right)=0$ and $a_{d}\left(i_{d}\right)=0$ for all $x_{w}, x_{d}, q_{w}, q_{d}, i_{d} \geq 0$. It is then easy to see that $D \leq f_{w}$ because $D>f_{w}$ implies excessive dam building. Observe also that under utilization of the dam by storing $y<D$ would imply suboptimal excessive dam building, and therefore, we must have $y=D$. Welfare optimization (9) reduces to the cost minimization program:

$$
\min _{D \geq 0} c_{w}\left(f_{w}-D\right)+c(D), \quad \text { s.t. } \quad D \leq f_{w} .
$$

Define $D^{*}$ as the unique solution to $c^{\prime}(D)=c_{w}^{\prime}\left(f_{w}-D\right)$. The following result is straightforward.

Proposition 4.1 If $c^{\prime}(0)<c_{w}^{\prime}\left(f_{w}\right)$, then the welfare optimal dam capacity is given by $D^{*} \in\left(0, f_{w}\right)$. Otherwise, the welfare optimal dam capacity is 0 .

This result shows that flooding will be mitigated by building dam capacity but never fully controlled. By applying implicit differentiation, it follows that $D^{*}$ is increasing in $f_{w}$. To see this, such differentiation with respect to $f_{w}$ implies

$$
c^{\prime \prime}\left(D^{*}\right) \cdot D^{* \prime}=c_{w}^{\prime \prime}\left(f_{w}-D^{*}\right) \cdot\left(1-D^{* \prime}\right)
$$

and hence,

$$
D^{* \prime}=\frac{c_{w}^{\prime \prime}\left(f_{w}-D^{*}\right)}{c_{w}^{\prime \prime}\left(f_{w}-D^{*}\right)+c^{\prime \prime}\left(D^{*}\right)} \in(0,1]
$$

because $c^{\prime \prime} \geq 0$ and $c_{w}^{\prime \prime}>0$. Constant marginal costs of dam building, as in Haddad (2010), implies $D^{* \prime}=1$, because $c^{\prime \prime}=0$. Then, increased inflow due to climate change (e.g. heavy rains) will be met by an equivalent increase in dam capacity. Under increasing marginal costs, 
we obtain $D^{* \prime}<1$ and increased inflow will only be partially met by increased dam capacity. In principle, the relation between inflow and welfare optimal dam capacity is nonlinear and increasing.

\subsection{Irrigation in the dry season}

Irrigation is the single largest consumptive use of fresh water in the world. Half of the world's largest dams were built exclusively or primarily for irrigation. As estimated $30-40 \%$ of the 268 million hectares of irrigated lands worldwide rely on dams (World Commission on Dams and Development, 2000). Based on our model we may obtain more detailed insights for the single purpose irrigation dam.

In the case of dam for irrigation purposes only, we have: $v_{w}\left(x_{w}\right)=0, v_{d}\left(x_{d}\right)=0$, $h_{w}\left(q_{w}\right)=0, h_{d}\left(q_{d}\right)=0$ and $c_{w}\left(f_{w}-y\right)=0$ for all $x_{w}, x_{d}, q_{w}, q_{d}, f_{w}-y \geq 0$. As before, we have $D \leq f_{w}$. Under utilization of the dam by storing $y<D$ would imply suboptimal excessive dam building, and therefore, we must have $y=D$. After substitution, the welfare function (9) becomes

$$
\begin{aligned}
& \max _{i_{d}, D} a_{d}\left(i_{d}\right)-c(D) \\
& \text { s.t. } \\
& \begin{array}{ll}
i_{d}-f_{d}-\delta D & \leq 0, \quad\left(\lambda_{d}\right) \\
D-f_{w} & \leq 0 . \quad\left(p_{w}\right)
\end{array}
\end{aligned}
$$

Observe that it is suboptimal to build dam capacity up to the level that meets the satiation level of irrigation $\bar{\imath}_{d}$, because $a_{d}^{\prime}\left(\bar{l}_{d}\right)=0<c^{\prime}(D)$. So, $i_{d}=f_{d}+\delta D<\bar{l}_{d}$, provided $f_{d}<\bar{l}_{d}$. Let $D^{*}\left(f_{d}\right) \in\left(0, \min \left\{f_{w}, \delta^{-1}\left(\bar{\imath}_{d}-f_{d}\right)\right\}\right)$ be the unique solution to $c^{\prime}(D)=\delta a_{d}^{\prime}\left(f_{d}+\delta D\right)>0$. Then, we have the following result.

Proposition 4.2 For $f_{d}<\bar{\imath}_{d}$ and $c^{\prime}(0)<\delta a_{d}^{\prime}\left(f_{d}\right)$, optimal management is given by
1. If $c^{\prime}\left(f_{w}\right) \leq \delta a_{d}^{\prime}\left(f_{d}+\delta f_{w}\right)$,
$D=f_{w}$
and $i_{d}=f_{d}+\delta f_{w}$,
2. If $c^{\prime}\left(f_{w}\right) \in\left(\delta a_{d}^{\prime}\left(f_{d}+\delta f_{w}\right), \delta a_{d}^{\prime}\left(f_{d}\right)\right)$,
$D=D^{*}\left(f_{d}\right)$
and $i_{d}=f_{d}+\delta D^{*}\left(f_{d}\right)$
and $D^{* \prime}\left(f_{d}\right)<0$.

Note that for the case of constant marginal costs of dam building we would have $D^{* \prime}\left(f_{d}\right)=$ $-\delta^{-1} \leq-1$, because $c^{\prime \prime}=0$. For $\delta=1$, it is -1 . 
The first case applies to arid regions. Then, harvesting all water in the wet season for use in the dry season is optimal if the marginal costs of dam capacity are lower than the marginal benefits from agriculture. Such practice is observed in e.g. the Jordan River where water resources for Israel and Jordan are harvested in Lake Tiberias and there is almost no river flow to the Dead Sea. The second case applies to semi-arid regions, where the wet season provides abundant precipitation and it is optimal to harvest only a fraction of it for use in the dry season. Then, the marginal costs of dam capacity are equated to the marginal benefits from agriculture. Such practice can be observed in e.g. the Ebro River basin in northern Spain.

There are two cases for which it is optimal not to build. This is the case if the condition of the above proposition does not hold, either $f_{d} \geq \bar{\imath}_{d}$, or $f_{d}<\bar{\imath}_{d}$ and $c^{\prime}(0) \geq \delta a_{d}^{\prime}\left(f_{d}\right)$. In the first case, river flow in the dry season is abundant to reach the satiation level $\bar{l}_{d}$, while in the second case $c^{\prime}(0)>0=\delta a_{d}^{\prime}\left(\bar{l}_{d}\right)$ says that the marginal cost of dam building lie above the marginal benefits of irrigated agriculture.

\subsection{Hydropower generation}

Hydropower used in over 150 countries provided 19\% of the world's total electricity supply around the millennium (World Commission on Dams and Development, 2000) and has increased to $24 \%$ today (NREL, 2014). If dam capacity are built for hydropower generation purposes only, we have the following relation: $v_{w}\left(x_{w}\right)=0, v_{d}\left(x_{d}\right)=0, a_{d}\left(i_{d}\right)=0, \bar{\imath}_{d}=0$ and $c_{w}\left(f_{w}-y\right)=0$ for all $x_{w}, x_{d}, i_{d}, f_{w}-y \geq 0$.

All these additional restrictions imply that, after substitution of $y=D-q_{w} \geq 0$, we consider the reduced optimization problem for $\delta \in(0,1]$ and the cost function $c(D)$ :

$$
\begin{aligned}
& \max _{q_{w}, q_{d}, D \geq 0} h_{w}\left(q_{w}\right)+h_{d}\left(q_{d}\right)-c(D), \\
& \text { s.t. } \\
& q_{d}-\delta D+\delta q_{w} \leq f_{d}, \quad\left(p_{d}\right) \\
& q_{d}-D \leq 0 . \quad\left(\mu_{d}\right)
\end{aligned}
$$

We have the same three cases as in Section 3.

Case 1': $q_{d}=f_{d}+\delta\left(D-q_{w}\right)<D$. As we will make clear in the appendix, this special case follows directly from the general Case 1 of section 3 . Let the pair $q_{w}^{*}$ and $q_{d}^{*}$ be the unique 
solution to

$$
h_{w}^{\prime}\left(q_{w}\right)=c^{\prime}\left(q_{w}+\delta^{-1}\left(q_{d}-f_{d}\right)\right) \text { and } \delta h_{d}^{\prime}\left(q_{d}\right)=c^{\prime}\left(q_{w}+\delta^{-1}\left(q_{d}-f_{d}\right)\right) .
$$

We have the following result.

Proposition 4.3 If $(1-\delta) q_{d}^{*}+\delta q_{w}^{*}>f_{d}$, then welfare optimal water management is given by hydropower generation $q_{w}^{*}<\bar{q}_{w}$ and $f_{d} \leq q_{d}^{*}<\bar{q}_{d}$, and building dam capacity $D^{*}=$ $q_{w}^{*}+\delta^{-1}\left(q_{d}^{*}-f_{d}\right) .^{4}$

This result has a straightforward interpretation. Water scarcity in the dry season to generate $q_{d}^{*}$ of hydropower implies a water deficit of $q_{d}^{*}-f_{d}$ in the dry season if no water would be stored during the wet season. This deficit is met by building dam capacity that exactly meets the optimal hydropower generation $q_{w}^{*}$ in the wet season plus the stored water needed to meet the water deficit $q_{d}-f_{d}$ in the dry season. The evaporation losses of stored water requires to store $\delta^{-1}\left(q_{d}^{*}-f_{d}\right)$ in the wet season. This is the case in arid and semi-arid regions in e.g. Africa, southeast Asia and the midwest of the US. The building cost of dam capacity make it optimal to install less capacity than $\bar{q}_{w}+\delta^{-1}\left(\bar{q}_{d}-f_{d}\right)$, i.e., the optimum levels under costless dam capacity building.

Case 2': $q_{d} \leq D<f_{d}+\delta\left(D-q_{w}\right)$. Although this special case also seems to follow directly from the general Case 2, there is an important caveat that we have to impose. Proceeding as in Case 1', let the pair $\hat{q}_{w}$ and $\hat{q}_{d}$ be the unique solution to

$$
c^{\prime}\left(q_{d}\right)=h_{w}^{\prime}\left(q_{w}\right)+h_{d}^{\prime}\left(q_{d}\right) \text { and } c^{\prime}\left(q_{d}\right)=\delta h_{d}^{\prime}\left(q_{d}\right) .
$$

Please note that (20) only holds when $q_{d}=D$. It yields inconsistency when $q_{d}=\bar{q}_{d}$.

Then, bearing in mind that $h_{w}^{\prime}\left(q_{w}\right) \geq 0$, we arrive at

$$
c^{\prime}\left(q_{d}\right)=h_{w}^{\prime}\left(q_{w}\right)+h_{d}^{\prime}\left(q_{d}\right) \geq h_{d}^{\prime}\left(q_{d}\right) \geq \delta h_{d}^{\prime}\left(q_{d}\right)
$$

All these inequalities can only hold if and only if $\delta=1$ and $q_{w}=\bar{q}_{w}$ such that $h_{w}^{\prime}\left(\bar{q}_{w}\right)=0$. So, this case can only hold for the unrealistic case of no evaporation losses $\delta=1$ from stored water. And then, (20) reduces to $\hat{q}_{d}$ is the unique solution to $c^{\prime}\left(q_{d}\right)=h_{d}^{\prime}\left(q_{d}\right)$. We have the following result.

\footnotetext{
${ }^{4}$ Note that $q_{d}^{*}<D^{*}=q_{w}^{*}+\delta^{-1}\left(q_{d}^{*}-f_{d}\right)$ imposes the condition $(1-\delta) q_{d}^{*}+\delta q_{w}^{*}>f_{d}$.
} 
Proposition 4.4 Only if $\delta=1$ and $\bar{q}_{w} \leq \hat{q}_{d} \leq f_{d}$ welfare optimal water management is given by hydropower generation $\hat{q}_{w}=\bar{q}_{w}$ and $\hat{q}_{d}<\bar{q}_{d}$, and building dam capacity $\hat{D}=\hat{q}_{d}$.

Loosely speaking, the above result implies an impossibility result for realistic values of evaporation losses of stored water, i.e., any $\delta<1$. Here we obtain an entirely different conclusion than Haddad (2011), who assumes $\delta=1$ and constant marginal costs of dam capacity building.

Case 3': $q_{d}=D=f_{d}+\delta\left(D-q_{w}\right)$. Proceeding as in Case 1', let $\tilde{q}_{w}$ and $\tilde{q}_{d}$ be the unique solution to

$$
h_{w}^{\prime}\left(q_{w}\right)=\delta h_{d}^{\prime}\left(q_{d}\right) \text { and }(1-\delta) q_{d}+\delta q_{w}=f_{d} .
$$

We have the following result.

Proposition 4.5 Welfare optimal water management is given by hydropower generation $\tilde{q}_{w}<\bar{q}_{w}$ and $f_{d} \leq \tilde{q}_{d}<\bar{q}_{d}$, and building dam capacity $\tilde{D}=\tilde{q}_{d}$.

By one of the binding constraints we have $(1-\delta) \tilde{q}_{d}+\delta \tilde{q}_{w}=f_{d}$ in the optimum. Rewriting in terms of the water deficit $\tilde{q}_{d}-f_{d}$ implies this deficit is equal to $\delta\left(\tilde{q}_{d}-\tilde{q}_{w}\right)$ in the dry season. So, a nonnegative water deficit requires $\delta^{-1}\left(\tilde{q}_{d}-f_{d}\right)$ of water storage in the wet season. Obviously, hydropower generation $\tilde{q}_{w}$ in the wet season is lower than hydropower generation $\tilde{q}_{d}$ in the dry season to allow for the optimal amount of water stored because $\tilde{D}=\tilde{q}_{d}$

\section{Concluding remarks}

To analyze the impact of dam capacity choice under rivalry use and externalities, we extend the hydropower generation model in Haddad (2011). Having included the competing use of water resources and non-linear building costs of dam capacity as well as the externalities of dams in a welfare optimization model, we obtained the optimal dam capacity for multifunctional dams such as providing infrastructure for industrial and households' water use, conjunctive use of hydropower generation and irrigation, reserving water in the wet season for use in the dry season and mitigating flooding damages. The optimal solution shows that optimal dam capacity depends on marginal benefits of hydropower generation and the 
constraining factors. The optimal water management can be achieved by using specific seasonal prices in a decentralized manner. This research offers useful insights and lays the foundation for a policy framework tailored to different development stages of water resource management in the presence of hydropower systems.

In this paper, we have not included issues such as salt water intrusion in the dry season, in order to keep our analysis tractable. It is, however, worthwhile to give some reflections on some relevant issues which are not formally discussed in the paper. Various extensions of this analysis can be considered such as saltwater intrusion in the estuary during the dry season, or the environmental function of water resources competing with irrigation $i_{d}$. Additional, in the dry season, outflow $o_{d}-i_{d}$ to the estuary combats saltwater intrusion with costs $c_{d}\left(o_{d}-i_{d}\right)$, a convex function $c_{d}(\cdot)$ with $c_{d}^{\prime}(\cdot)<0$. Therefore the costs decrease when more fresh water flows into the estuary. We regard irrigation $i_{d}$ as irrigation at elevated inland plots that are immune to saltwater intrusion, and irrigation on plots at the lowest parts of the delta can be included as benefits in the costs function for saltwater intrusion. Moreover, we can replace $a_{d}\left(i_{d}\right)$ by $a_{d}\left(i_{d}\right)-c_{d}\left(o_{d}-i_{d}\right)$ and $a_{d}^{\prime}\left(i_{d}\right)$ by $a_{d}^{\prime}\left(i_{d}\right)-c_{d}^{\prime}\left(o_{d}-i_{d}\right)$. Therefore, $i_{d}$ increasing implies both $a_{d}^{\prime}$ and $c_{d}^{\prime}$ are increasing, whereas, $o_{w}$ increasing implies $c_{d}^{\prime}$ decreasing. Restoring nature in wet season, both functions $n_{w}\left(o_{w}\right)$ and $n_{w}^{\prime}\left(o_{w}\right)$ are positive. In the future work, we will present further details of feasible extensions and an empirical analysis.

\section{Appendix: Derivations}

In this appendix, we derive the main results discussed in Section 3. Optimization program (9) is strictly convex and, therefore, it allows a unique welfare optimum with nonnegative shadow prices. Moreover, water using activities such as consumptive use by industry and households, hydropower generation, irrigation and storage of water have the property of free disposal, i.e., agents are not forced to consume excess water. Consequently, the marginal benefits of these activities are nonnegative. Formally, in the optimum it holds that $v_{\tau}^{\prime}\left(x_{\tau}\right) \geq 0, h_{\tau}^{\prime}\left(q_{\tau}\right) \geq 0$ for $\tau=w, d$ and $a_{d}^{\prime}\left(i_{d}\right) \geq 0$. 
The Lagrangian function of system (9) is given by

$$
\begin{aligned}
& v_{w}\left(x_{w}\right)+v_{d}\left(x_{d}\right)+h_{w}\left(q_{w}\right)+h_{d}\left(q_{d}\right)+a_{d}\left(i_{d}\right)-c(D)-c_{w}\left(q_{w}-D+f_{w}\right) \\
& -p_{d}\left[\delta x_{w}+x_{d}+\delta q_{w}+q_{d}-\delta D-f_{d}\right]-\mu_{d}\left[x_{d}+q_{d}-D\right] \\
& -\lambda_{d}\left[\delta x_{w}+x_{d}+\delta q_{w}+i_{d}-\delta D-f_{d}\right] .
\end{aligned}
$$

The first-order-conditions for a positive solution, i.e. $x_{w}, x_{d}, q_{w}, q_{d}, i_{d}, D>0$, are

$$
\begin{aligned}
& x_{w}: \\
& v_{w}^{\prime}\left(x_{w}\right)-\delta p_{d}-\delta \lambda_{d}=0 \\
& x_{d}: \quad v_{d}^{\prime}\left(x_{d}\right)-p_{d}-\lambda_{d}-\mu_{d}=0 \text {, } \\
& q_{w}: \quad h_{w}^{\prime}\left(q_{w}\right)-c_{w}^{\prime}\left(f_{w}+q_{w}-D\right)-\delta p_{d}-\delta \lambda_{d}=0 \text {, } \\
& q_{d}: \quad h_{d}^{\prime}\left(q_{d}\right)-p_{d}-\mu_{d}=0 \text {, } \\
& i_{d}: \quad a_{d}^{\prime}\left(i_{d}\right)-\lambda_{d}=0 \text {, } \\
& D:-c^{\prime}(D)+c_{w}^{\prime}\left(f_{w}+q_{w}-D\right)+\delta p_{d}+\delta \lambda_{d}+\mu_{d}=0 \text {, } \\
& p_{d}\left[x_{d}+q_{d}-f_{d}-\delta\left(D-x_{w}-q_{w}\right)\right]=0, \\
& \lambda_{d}\left[i_{d}-\delta\left(D-x_{w}-q_{w}\right)-f_{d}+x_{d}\right]=0 \text {, } \\
& \mu_{d}\left[x_{d}+q_{d}-D\right]=0 .
\end{aligned}
$$

Proof of Proposition 3.1. From $(22), \lambda_{d}=a_{d}^{\prime}\left(i_{d}\right)$ is straightforward. Then,

$\lambda_{d}\left[i_{d}-\delta\left(D-x_{w}-q_{w}\right)-f_{d}+x_{d}\right]=0$ implies either $\lambda_{d}=a_{d}^{\prime}\left(i_{d}\right)=0$ and in turn $i_{d}=\bar{\imath}_{d}$, or $i_{d}=q_{d}$ and in turn $a_{d}^{\prime}\left(i_{d}\right) \geq 0$. So,

$$
i_{d}=\min \left\{\bar{\imath}_{d}, q_{d}\right\}
$$

By $\lambda_{d}=a_{d}^{\prime}\left(i_{d}\right)$ and from combining the first and third line of (22) and the second and fourth line of (22), we obtain:

$$
\begin{aligned}
& v_{w}^{\prime}\left(x_{w}\right)=h_{w}^{\prime}\left(q_{w}\right)-c_{w}^{\prime}\left(f_{w}+q_{w}-D\right), \\
& v_{d}^{\prime}\left(x_{d}\right)=h_{d}^{\prime}\left(q_{d}\right)+a_{d}^{\prime}\left(i_{d}\right) .
\end{aligned}
$$

Note that $v_{w}^{\prime}\left(x_{w}\right) \geq 0$ implies that $h_{w}^{\prime}\left(q_{w}\right) \geq c_{w}^{\prime}\left(f_{w}+q_{w}-D\right)$. Whatever the optimum, these conditions must always hold.

Proof of Proposition 3.2. By the fourth line of $(22), \mu_{d}+p_{d}=h_{d}^{\prime}\left(q_{d}\right)$, and then, by the nonnegativity of shadow prices, $p_{d}, \mu_{d} \in\left[0, h_{d}^{\prime}\left(q_{d}\right)\right]$. After substituting the third line of $(22)$ into the sixth line of $(22)$, we obtain

$$
\mu_{d}=c^{\prime}(D)-h_{w}^{\prime}\left(q_{w}\right)
$$

So, $\mu_{d} \geq 0$ implies $c^{\prime}(D) \geq h_{w}^{\prime}\left(q_{w}\right)$ and $\mu_{d} \leq h_{d}^{\prime}\left(q_{d}\right)$ implies $c^{\prime}(D) \leq h_{w}^{\prime}\left(q_{w}\right)+h_{d}^{\prime}\left(q_{d}\right)$. Then by $\mu_{d}+p_{d}=h_{d}^{\prime}\left(q_{d}\right)$, we obtain

$$
p_{d}=h_{d}^{\prime}\left(q_{d}\right)+h_{w}^{\prime}\left(q_{w}\right)-c^{\prime}(D) \in\left[0, h_{d}^{\prime}\left(q_{d}\right)\right] .
$$


Whatever the optimum, these conditions must always hold.

Proof of Proposition 3.3-3.5. As derived in the main text, combining both propositions yields $c_{w}^{\prime}\left(f_{w}+q_{w}-D\right) \leq h_{w}^{\prime}\left(q_{w}\right) \leq c^{\prime}(D)$. The solution to (9) depends upon whether the water availability (3) or dam capacity (7) restricts water use and hydropower generation in the dry season. Water availability is the binding constraint whenever $(1-\delta) D+$ $\delta\left(x_{w}+q_{w}\right)>f_{d}$. In the following, we distinguish three cases based upon $>,<$ and $=$.

Case 1: $(1-\delta) D+\delta\left(x_{w}+q_{w}\right)>f_{d}$

Then, $x_{d}+q_{d} \leq f_{d}+\delta\left(D-x_{w}-q_{w}\right)<D$. The last inequality imposes $\mu_{d}=0$. By Proposition $3.2, h_{w}^{\prime}\left(q_{w}\right)=c^{\prime}(D)>0$ and $p_{d}=h_{d}^{\prime}\left(q_{d}\right)$. Then also, $h_{w}^{\prime}\left(q_{w}\right)>0$ implies $q_{w}<\bar{q}_{w}$. From combining $\mu_{d}=0$ and the first and second line of $(22)$, we obtain $v_{w}^{\prime}\left(x_{w}\right)=$ $\delta v_{d}^{\prime}\left(x_{d}\right)$. These results and Proposition 3.1 imply the upper five lines of (12). There are two subcases:

Case 1A: $x_{d}+q_{d}<f_{d}+\delta\left(D-x_{w}-q_{w}\right)$. Then also $p_{d}=0$, and $h_{d}^{\prime}\left(q_{d}\right)=p_{d}+\mu_{d}=0$ imposes $q_{d}=\bar{q}_{d}$. So, $i_{d}=\min \left\{\bar{\imath}_{d}, \bar{q}_{d}\right\}$. The remaining variables $x_{w}, x_{d}, q_{w}, D>0$ solve the upper four lines of (12).

Case 1B: $x_{d}+q_{d}=f_{d}+\delta\left(D-x_{w}-q_{w}\right)$. Then $x_{w}, x_{d}, q_{w}, q_{d}, i_{d}, D>0$ solve this constraint and the upper five lines of (12).

Combining both subcases implies that $x_{w}, x_{d}, q_{w}, q_{d}, i_{d}, D>0$ solve the upper five lines of (12) and either $x_{d}+q_{d}=f_{d}+\delta\left(D-x_{w}-q_{w}\right)$ or $q_{d}=\bar{q}_{d}$. This proves Proposition 3.3.

Case 2: $(1-\delta) D+\delta\left(x_{w}+q_{w}\right)<f_{d}$

Then, $x_{d}+q_{d} \leq D<f_{d}+\delta\left(D-x_{w}-q_{w}\right)$. The last inequality imposes $p_{d}=0$ and, by Proposition 3.2, $h_{d}^{\prime}\left(q_{d}\right)+h_{w}^{\prime}\left(q_{w}\right)=c^{\prime}(D)$ and $\mu_{d}=h_{d}^{\prime}\left(q_{d}\right)$. Combining the first and second line of $(22)$ and substituting the shadow prices, we obtain $v_{w}^{\prime}\left(x_{w}\right)=\delta\left[v_{d}^{\prime}\left(x_{d}\right)-h_{d}^{\prime}\left(q_{d}\right)\right]$. These results and Proposition 3.1 imply the upper five lines of (14). There are again two subcases:

Case 2A: $x_{d}+q_{d}<D$. Then, also $\mu_{d}=0$ and similar as in case 1.A, $h_{d}^{\prime}\left(q_{d}\right)=0$ and $q_{d}=\bar{q}_{d}$. Then also $h_{w}^{\prime}\left(q_{w}\right)=c^{\prime}(D)>0$ and $q_{w}<\bar{q}_{w}$ must hold. Then the remaining variables $x_{w}, x_{d}, q_{w}, i_{d}, D>0$ solve the upper five lines of (14). 
Case 2B: $x_{d}+q_{d}=D$. Then $x_{w}, x_{d}, q_{w}, q_{d}, i_{d}, D>0$ solve this constraint and the upper five lines of (14).

Combining both subcases implies that $x_{w}, x_{d}, q_{w}, q_{d}, i_{d}, D>0$ solve the upper five lines of (14) and either $x_{d}+q_{d}=f_{d}+\delta\left(D-x_{w}-q_{w}\right)$ or $q_{d}=\bar{q}_{d}$. This proves Proposition 3.4.

Case 3: $(1-\delta) D+\delta\left(x_{w}+q_{w}\right)=f_{d}$

Then, $x_{d}+q_{d} \leq f_{d}+\delta\left(D-x_{w}-q_{w}\right)=D$. The equality constraint can be rewritten as $(1-\delta) D=f_{d}-\delta\left(x_{w}+q_{w}\right)$. Since we solve for $D>0$, we must have that $f_{d}>\delta\left(x_{w}+q_{w}\right)$. By Proposition 3.2, $\mu_{d}+p_{d}=h_{d}^{\prime}\left(q_{d}\right)$. From combining the first and second line of $(22)$, we obtain $\mu_{d}=v_{d}^{\prime}\left(x_{d}\right)-\delta^{-1} v_{w}^{\prime}\left(x_{w}\right)$. These results and Proposition 3.1 imply the upper five lines of (15). Similar as before, there are two subcases:

Case 3A: $x_{d}+q_{d}<f_{d}+\delta\left(D-x_{w}-q_{w}\right)=D$. Then, $\mu_{d}=p_{d}=0$ and for reasons similar as in case $1 . \mathrm{A}, q_{d}=\bar{q}_{d}$. So, the remaining variables $x_{w}, x_{d}, q_{w}, i_{d}, D>0$ solve the upper five lines of (15), where $v_{d}^{\prime}\left(x_{d}\right)=\delta^{-1} v_{w}^{\prime}\left(x_{w}\right)$ holds due to $\mu_{d}=0$.

Case 3B: $x_{d}+q_{d}=D$. Then, $\mu_{d}, p_{d} \geq 0$ and $x_{w}, x_{d}, q_{w}, q_{d}, i_{d}>0$ solve this constraint and the upper five lines of (15).

Combining both subcases implies that $x_{w}, x_{d}, q_{w}, q_{d}, i_{d}, D>0$ solve solve the upper five lines of (15) and either $x_{d}+q_{d}=D$ or $\left[q_{d}=\bar{q}_{d}\right.$ and $\left.\mu_{d}=p_{d}=0\right]$.

Water stored is in nonnegative amounts, which imposes $D \geq x_{w}+q_{w}$. In addition to Proposition 3.1, $\mu_{d} \in\left[0, h_{d}^{\prime}\left(q_{d}\right)\right]$ imposes

$$
v_{w}^{\prime}\left(x_{w}\right) \leq \delta v_{d}^{\prime}\left(x_{d}\right) \leq \delta h_{d}^{\prime}\left(q_{d}\right)+v_{w}^{\prime}\left(x_{w}\right) .
$$

\section{This proves Proposition 3.5.}

Proof of Proposition 4.2. From (22), the first-order-conditions for a positive solution, i.e. $i_{d}, D>0$, in this special case are

$$
\begin{aligned}
i_{d}: \quad a_{d}^{\prime}\left(i_{d}\right)-\lambda_{d} & =0 \\
D:-c^{\prime}(D)+\delta \lambda_{d}-p_{w} & =0 \\
\lambda_{d}\left(i_{d}-f_{d}-\delta D\right) & =0 \\
p_{w}\left(D-f_{w}\right) & =0
\end{aligned}
$$


By Proposition 3.1, we have that $\lambda_{d}=a_{d}^{\prime}\left(i_{d}\right)$ and, therefore, $p_{w}=\delta a_{d}^{\prime}\left(i_{d}\right)-c^{\prime}(D)$. Nonnegativity of $p_{w}$ implies $\delta a_{d}^{\prime}\left(i_{d}\right) \geq c^{\prime}(D)>0$ and, thus, both $i_{d}<\bar{\imath}_{d}$ and $\lambda_{d}>0$. Then, $i_{d}=f_{d}+\delta D$ holds. There are two cases to consider:

- If $D=f_{w}$. Then, $p_{w} \geq 0, i_{d}=f_{d}+\delta f_{w}$ and $D=f_{w}$ can only be optimal if $\delta a_{d}^{\prime}\left(f_{d}+\delta f_{w}\right) \geq c^{\prime}\left(f_{w}\right)$.

- If $D \in\left(0, f_{w}\right)$, then $p_{w}=0$ implies $\delta a_{d}^{\prime}\left(i_{d}\right)=c^{\prime}(D)>0$. Combined with $i_{d}=$ $f_{d}+\delta D$, we obtain that $D$ solves $c^{\prime}(D)=\delta a_{d}^{\prime}\left(f_{d}+\delta D\right)>0$, which is $D^{*}\left(f_{d}\right)$. Since $c^{\prime}(D)$ is increasing in $D$, and $\delta a_{d}^{\prime}\left(f_{d}+\delta D\right)$ is decreasing in $D$, there exists a unique intersection point $D \in\left(0, f_{w}\right)$ if and only if both $c^{\prime}(0)<\delta a_{d}^{\prime}\left(f_{d}\right)$ and $c^{\prime}\left(f_{w}\right)>\delta a_{d}^{\prime}\left(f_{d}+\delta f_{w}\right)$. Since $i_{d}<\bar{\imath}_{d}$, we also have $f_{d}+\delta D<\bar{\imath}_{d}$, or $D<\delta^{-1}\left(\bar{\imath}_{d}-f_{d}\right)$. So, $D<\min \left\{f_{w}, \delta^{-1}\left(\bar{\imath}_{d}-f_{d}\right)\right\}$.

Implicit differentiation of $c^{\prime}\left(D^{*}\left(f_{d}\right)\right)=\delta a_{d}^{\prime}\left(f_{d}+\delta D^{*}\left(f_{d}\right)\right)$ with respect to $f_{d}$ yields

$$
c^{\prime \prime}\left(D^{*}\left(f_{d}\right)\right) \cdot D^{* \prime}\left(f_{d}\right)=\delta a_{d}^{\prime \prime}\left(f_{d}+\delta D^{*}\left(f_{d}\right)\right) \cdot\left[1+\delta D^{* \prime}\left(f_{d}\right)\right]
$$

which implies

$$
D^{* \prime}\left(f_{d}\right)=\frac{\delta a_{d}^{\prime \prime}\left(f_{d}+\delta D^{*}\left(f_{d}\right)\right)}{c^{\prime \prime}\left(D^{*}\left(f_{w}\right)\right)-\delta^{2} \delta a_{d}^{\prime \prime}\left(f_{d}+\delta D^{*}\left(f_{d}\right)\right)}<0,
$$

because $c^{\prime \prime} \geq 0$ and $a_{d}^{\prime \prime}<0$. This completes the proof.

Proof of Proposition 4.3 - 4.5. From (22), the first-order-conditions for a positive solution, i.e. $q_{w}, q_{d}, D>0$, in this special case are

$$
\begin{aligned}
& q_{w}: \quad h_{w}^{\prime}\left(q_{w}\right)-\delta p_{d}=0, \\
& q_{d}: \quad h_{d}^{\prime}\left(q_{d}\right)-p_{d}-\mu_{d}=0 \text {, } \\
& D: \quad-c^{\prime}(D)+\delta p_{d}+\mu_{d}=0 \text {, } \\
& p_{d}\left[q_{d}-f_{d}-\delta\left(D-q_{w}\right)\right]=0 \text {, } \\
& \mu_{d}\left[q_{d}-D\right]=0 \text {. }
\end{aligned}
$$

Recall that $D \geq q_{w}$ also holds. So, $D \geq \max \left\{q_{w}, q_{d}\right\}$. There are three cases to consider.

1. $q_{d} \leq f_{d}+\delta\left(D-q_{w}\right)<D$. Then, $\mu_{d}=0$ and Proposition 3.2 imply $h_{w}^{\prime}\left(q_{w}\right)=$ $c^{\prime}(D)>0$, and $(13)$ imposes $\delta h_{d}^{\prime}\left(q_{d}\right)=c^{\prime}(D)>0$. So, $q_{w}<\bar{q}_{w}$ and $q_{d}<\bar{q}_{d}$. The last inequality imposes $q_{d}=f_{d}+\delta\left(D-q_{w}\right) \geq f_{d}$, because water stored is in nonnegative amounts, i.e., $D-q_{w} \geq 0$, and $h_{d}^{\prime}\left(q_{d}\right)>0$ while $q_{d}<f_{d}+\delta\left(D-q_{w}\right)$ is suboptimal. The binding constraint yields $D=q_{w}+\delta^{-1}\left(q_{d}-f_{d}\right)$ and after substitution into $c^{\prime}(D)=h_{w}^{\prime}\left(q_{w}\right)=\delta h_{d}^{\prime}\left(q_{d}\right)$ we obtain (19). This proves Proposition 4.3 
2. $q_{d} \leq D<f_{d}+\delta\left(D-q_{w}\right)$. Then, $p_{d}=0$ and Proposition 3.2 imply $c^{\prime}(D)=h_{w}^{\prime}\left(q_{w}\right)+$ $h_{d}^{\prime}\left(q_{d}\right)$. Recall from the main text that (13) also holds for Case 2, so $\delta h_{d}^{\prime}\left(q_{d}\right)=c^{\prime}(D)>$ 0 . As in Case 1', we have $q_{d}<\bar{q}_{d}$. In this case, $q_{d}=D$ has to hold, because otherwise $q_{d}<D<f_{d}+\delta\left(D-q_{w}\right)$ while $h_{d}^{\prime}\left(q_{d}\right)>0$ is suboptimal. So, after substitution of $D=q_{d}$ into $c^{\prime}(D)=h_{w}^{\prime}\left(q_{w}\right)+h_{d}^{\prime}\left(q_{d}\right)=\delta h_{d}^{\prime}\left(q_{d}\right)$ we obtain $(20)$. By $h_{w}^{\prime}\left(q_{w}\right) \geq 0$, we have

$$
c^{\prime}\left(q_{d}\right)=h_{w}^{\prime}\left(q_{w}\right)+h_{d}^{\prime}\left(q_{d}\right) \geq h_{d}^{\prime}\left(q_{d}\right) \geq \delta h_{d}^{\prime}\left(q_{d}\right)
$$

and these inequalities can only hold if and only if $\delta=1$ and $q_{w}=\bar{q}_{w}$ such that $h_{w}^{\prime}\left(\bar{q}_{w}\right)=0$. This proves Proposition 4.4

3. $q_{d} \leq D=f_{d}+\delta\left(D-q_{w}\right)$. Recall from the main text that (16) holds for Case 3, so $\mu_{d}=c^{\prime}(D)-\delta h_{d}^{\prime}\left(q_{d}\right)$. By Proposition 3.2, we also have $\mu_{d}=c^{\prime}(D)-h_{w}^{\prime}\left(q_{w}\right)$. So,

$h_{w}^{\prime}\left(q_{w}\right)=\delta h_{d}^{\prime}\left(q_{d}\right)$ must hold. Substitution of the last equality into Proposition 3.2 yields

$$
\delta h_{d}^{\prime}\left(q_{d}\right) \leq c^{\prime}(D) \leq(1+\delta) h_{d}^{\prime}\left(q_{d}\right)
$$

and due to $c^{\prime}(D)>0$ this imposes $h_{d}^{\prime}\left(q_{d}\right)>0$ and $q_{d}<\bar{q}_{d}$. This imposes $q_{d}=D$, because otherwise $q_{d}<D=f_{d}+\delta\left(D-q_{w}\right)$ while $h_{d}^{\prime}\left(q_{d}\right)>0$ is suboptimal. After substitution of $D=q_{d}$ into the binding constraint (21) follows. Because water stored is in nonnegative amounts, i.e., $D-q_{w} \geq 0, q_{d}=D=f_{d}+\delta\left(D-q_{w}\right) \geq f_{d}$. This proves Proposition 4.5

\section{References}

Beck, M., A. Claassen \& P. Hundt (2012) Environmental and livelihood impacts of dams: common lessons across development gradients that challenge sustainability, International Journal of River Basin Management, 10 (1): 73-92 (DOI: 10.1080/15715124.2012.656133)

Cornish C., B. Bosworth, C. Perry \& J. Burke (2004) Water charging in irrigated agriculture: An analysis of international experience, FAO Water Report, 28. 
Dugan, P.J; C. Barlow, A. Agostinho, E. Baran, G. Cada, D. Chen, I. Cowx, J. Ferguson, T. Jutagate, M. Mallen-Cooper, G. Marmulla, J. Nestler, M. Petrere, R. Welcomme \& K. Winemiller (2010) Fish Migration, Dams, and Loss of Ecosystem Services in the Mekong Basin, AMBIO: A Journal of the Human Environment 39 (4):344-348 (http://www.bioone.org/doi/pdf/10.1007/s13280-010-0036-1)

Haddad, M.S.(2011) Capacity choice and water management in hydroelectricity systems. Energy Economics 33: 168-177

Houba,H., K.H Pham Do and X. Zhu (2013) Saving a River: a Joint Management Approach to the Mekong, Environment and Development Economics 18: 93-109

NREL (2014) Hydroelectric Power (http://www.waterencyclopedia.com/Ge-Hy/HydroelectricPower.html.)

World Commission on Dams and Development (2000): A new Framework for DecisionMaking, The report of the World commission on Dams.

Zhu, X. and E.C. van Ierland (2012) Economic modelling for water quantity and quality management: a welfare program approach, Water Resources Management 26: 2491-2511. 